\title{
Vivenciando Ciência e Tecnologia de Polímeros
}

Este número de "Polímeros: Ciência e Tecnologia" chega às mãos do leitor no momento em que se realiza em Salvador - Bahia, o $4^{\circ}$ Congresso Brasileiro de Polímeros. Nesta sua quarta edição, nosso congresso apresenta cinco micro-simpósios dedicados a Compósitos e Blendas Poliméricas, Membranas Poliméricas, Polímeros Naturais, Processamento e Reciclagem de Polímeros e Síntese e Caracterização de Polímeros. Temos certeza de que em mais esta jornada técnico-científica os participantes serão contemplados com muitas oportunidades de aprendizado e troca de experiências que deverão contribuir para o crescimento e consolidação da Ciência de Polímeros em nosso país.

Como reconhecimento por suas atividades, a ABPol foi escolhida para coordenar as atividades de uma Entidade Tecnológica Setorial na área de Polímeros (ETS-Polímeros); esta entidade será um importante veículo para a definição e difusão de políticas para $\mathrm{P} \& \mathrm{D}$ a nível nacional, relativas a área de Ciência e Tecnologia de Polímeros. A matéria dedicada ao assunto apresenta uma rápida visão da situação atual dos polímeros no Brasil e destaca os principais pontos que levam a ABPol a liderar a constituição de uma ETS-Polímeros.

Esta edição apresenta ainda uma entrevista com o diretor do Center for Polymer Research da Universidade de Texas em Austin, Professor Donald R. Paul, mundialmente reconhecido por sua contribuição para a área de pesquisas em blendas e membranas poliméricas. Nesta entrevista, o Prof. Paul descreve as atividades do "Center for Polymer Research" e apresenta suas opiniões a respeito de importantes aspectos de $\mathrm{P} \& \mathrm{D}$ na área de polímeros.

A partir desta edição nossa revista passará a contar na sua seção editorial com matérias e artigos especialmente preparados a convite do Comitê Editorial. O artigo de estréia é dedicado à "Análise de falhas em materiais através de Técnicas avançadas de microscopia" e visa difundir as potencialidades desta técnica junto aos pesquisadores que se dedicam ao estudo de materiais poliméricos.

Informamos aos leitores que utilizam o "Chemical Abstracts" e "RAPRA Abstracts"que nossa revista está indexada como Polim: Cienc. Tecnol.

Desejamos aos participantes do $4^{\circ}$ Congresso uma excelente jornada de trabalho e aos que não puderam atender ao congresso, uma excelente leitura.

Comitê Editorial 